\title{
Friedel-Crafts Acylation of Furan: Development of A Green Process Using Chromium-exchanged Dodecatungstophosphoric Acid: Effect of Support, Mechanism and Kinetic Modelling
}

\section{Deepak S. Desai}

Institute of Chemical Technology

Ganapati D. Yadav ( $\square$ gdyadav@yahoo.com )

Institute of Chemical Technology Mumbai https://orcid.org/0000-0002-8603-3959

\section{Research Article}

Keywords: Friedel Crafts Acylation, Heteropoly acid, Chromium exchanged dodecatungstophosphoric acid, Clay, Eley-Rideal Mechanism, Kinetics, Green Chemistry

Posted Date: February 24th, 2021

DOl: https://doi.org/10.21203/rs.3.rs-234024/v1

License: (c) (1) This work is licensed under a Creative Commons Attribution 4.0 International License. Read Full License

Version of Record: A version of this preprint was published at Clean Technologies and Environmental Policy on July 23rd, 2021. See the published version at https://doi.org/10.1007/s10098-021-02162-4. 


\section{Abstract}

The Friedel-Crafts acylation of furan with acetic anhydride to produce 2-acyl furan is industrially important. With an aim of replacing the highly polluting process, it this study, supported but modified heteropoly acids were used. Metal exchanged dodecatungstophosphoric acid (DTP) was loaded on three different supports and its effect on acylation was evaluated. Thus, chromium exchanged DTP was supported on $\mathrm{K}-10, \mathrm{SiO}_{2}$, and $\mathrm{ZrO}_{2}$ using the incipient wetness impregnation method. $20 \% \mathrm{w} / \mathrm{w} \mathrm{Cr}_{0.66^{-}}$ DTP/K-10 having the best activity for the acylation of furan with acetic anhydride was chosen for full characterization and reaction kinetics. Under optimized condition, the catalyst to furan ratio was $9.6 \%$, significantly less as per prior art, which gave $88 \%$ conversion with $100 \%$ selectivity. The prepared catalysts were characterized by sophisticated techniques, namely, XRD, FT-IR, SEM, $\mathrm{NH}_{3}-\mathrm{TPD}, \mathrm{TGA}$, and BET. The Eley-Rideal mechanism was found to fit the kinetic data. The activation energy was found to be $18.03 \mathrm{kcal} / \mathrm{mol}$. The reaction is green and clean as no chlorinated chemicals, reagents, and catalysts were used.

\section{Full Text}

Due to technical limitations, full-text HTML conversion of this manuscript could not be completed. However, the latest manuscript can be downloaded and accessed as a PDF.

\section{Tables}

Table 1. $\mathrm{NH}_{3}$-TPD and Surface area, pore volume, and pore diameter of K-10 supported catalysts.

\begin{tabular}{|c|c|c|c|c|c|c|c|}
\hline Sr. & Catalyst & Aci & lity $\left(\mathrm{mmol}\right.$ of $\mathrm{NH}_{3}$ & $-1)$ & Surface & Pore & Pore \\
\hline & & Weak & Moderate/Strong & Total & & & \\
\hline 1 & $\mathrm{~K}-10$ & 0.68 & 0.19 & 0.86 & 240 & 6 & 0.39 \\
\hline 2 & $20 \% \mathrm{w} / \mathrm{w}$ DTP $/ \mathrm{K}-10$ & 0.77 & 1.02 & 1.79 & 107.3 & 7.4 & 0.32 \\
\hline 3 & $\begin{array}{c}20 \% \mathrm{w} / \mathrm{w} \mathrm{Cr} \mathrm{Cr}_{0.66^{-}} \\
\text {DTP/K-10 }\end{array}$ & 0.85 & 1.22 & 2.07 & 145.6 & 7 & 0.3 \\
\hline 4 & $\begin{array}{l}\text { Reused } 20 \% \mathrm{w} / \mathrm{w} \\
\mathrm{Cr}_{0.66}-\mathrm{DTP} / \mathrm{K}-10\end{array}$ & 0.83 & 1.21 & 2.04 & 143.1 & 7.1 & 0.3 \\
\hline
\end{tabular}

Table 2. Kinetic parameters of acylation of furan with acetic anhydride at various temperature. 


\begin{tabular}{|c|c|c|c|c|}
\hline Sr. No. & $\mathrm{T}(\mathrm{K})$ & $\begin{array}{c}\mathrm{k} \\
\left(\mathrm{cm}^{6} \mathrm{~mol}^{-1} \mathrm{~g}^{-1} \mathrm{~s}^{-1}\right)\end{array}$ & $\begin{array}{c}\mathrm{K}_{\mathrm{B}} \\
\left(\mathrm{cm}^{3} \mathrm{~mol}^{-1}\right)\end{array}$ & $\begin{array}{c}\text { Activation energy (E) } \\
\left(\mathrm{kcal} \mathrm{mol}^{-1}\right)\end{array}$ \\
\hline 1. & 303 & 0.036 & 0.014 & \\
\hline 2. & 313 & 0.082 & 0.011 & 18.03 \\
\hline 3. & 323 & 0.240 & 0.007 & \\
\hline 4. & 333 & 0.510 & 0.004 & \\
\hline
\end{tabular}

\section{Figures}

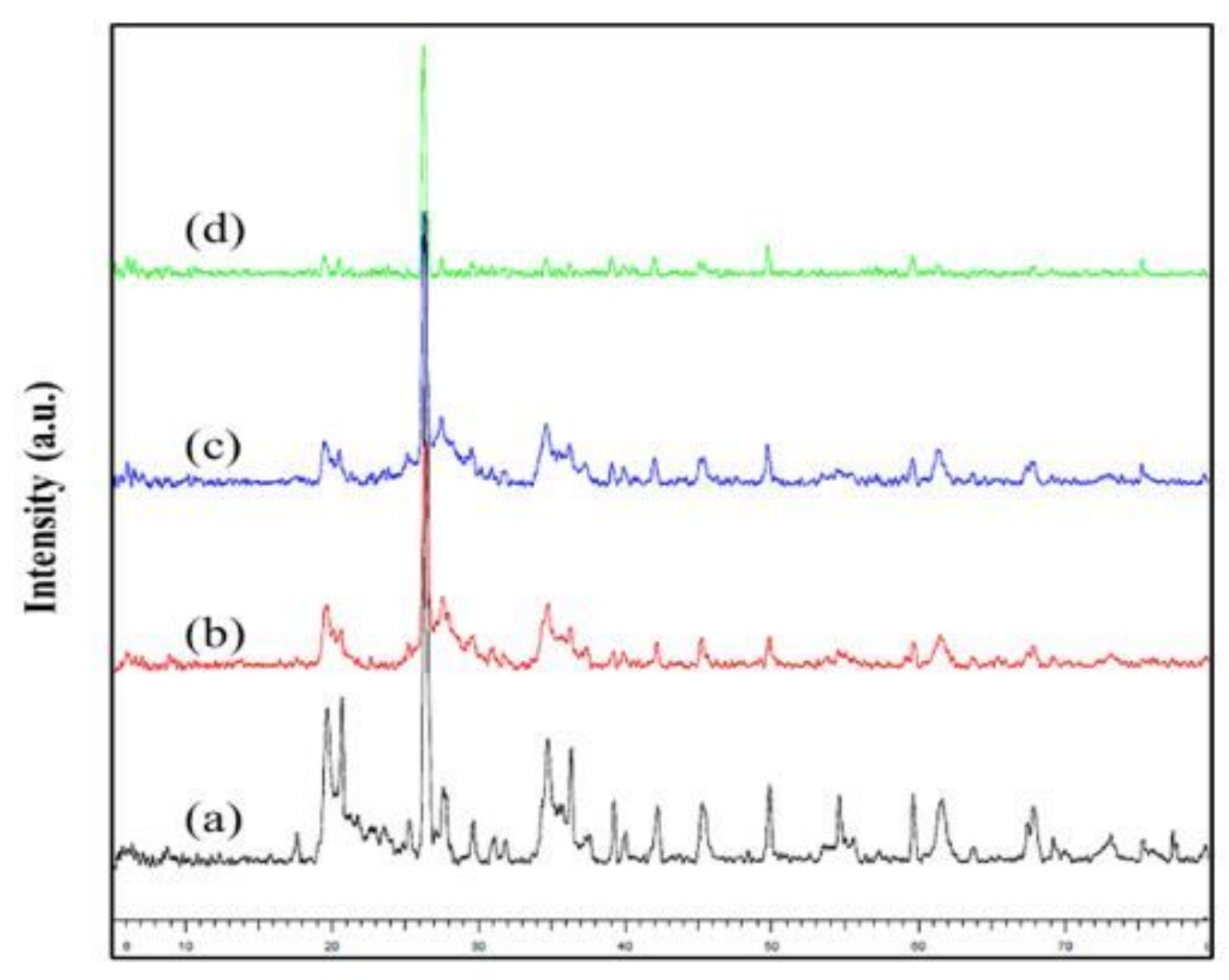

2-Theta scale

Figure 1

XRD of (a) K-10, (b) 20\% w/w DTP/K-10, (c) $20 \%$ w/w Cr0.66-DTP/K-10, and (d) reused 20\% w/w Cr0.66DTP/K-10. 


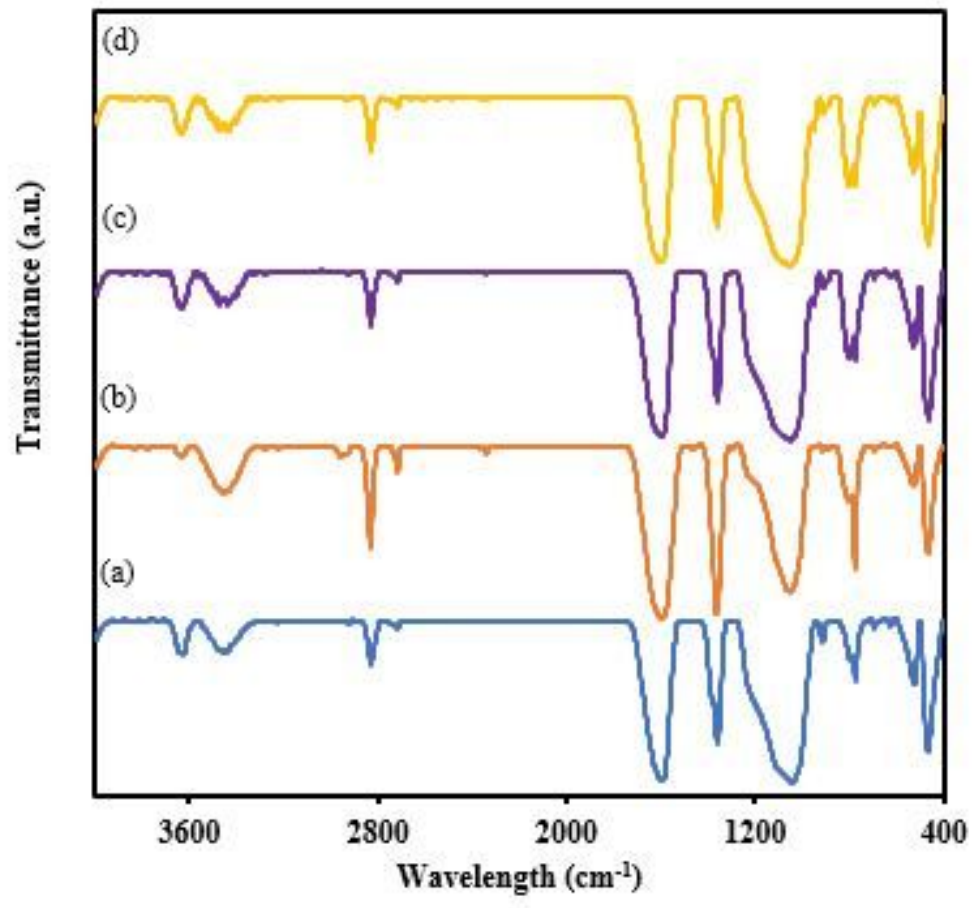

Figure 2

FT-IR of (a) K-10, (b) 20\% w/w DTP/K-10, (c) $20 \%$ w/w Cr0.66-DTP/K-10, and (d) reused 20\% w/w Cr0.66DTP/K-10.

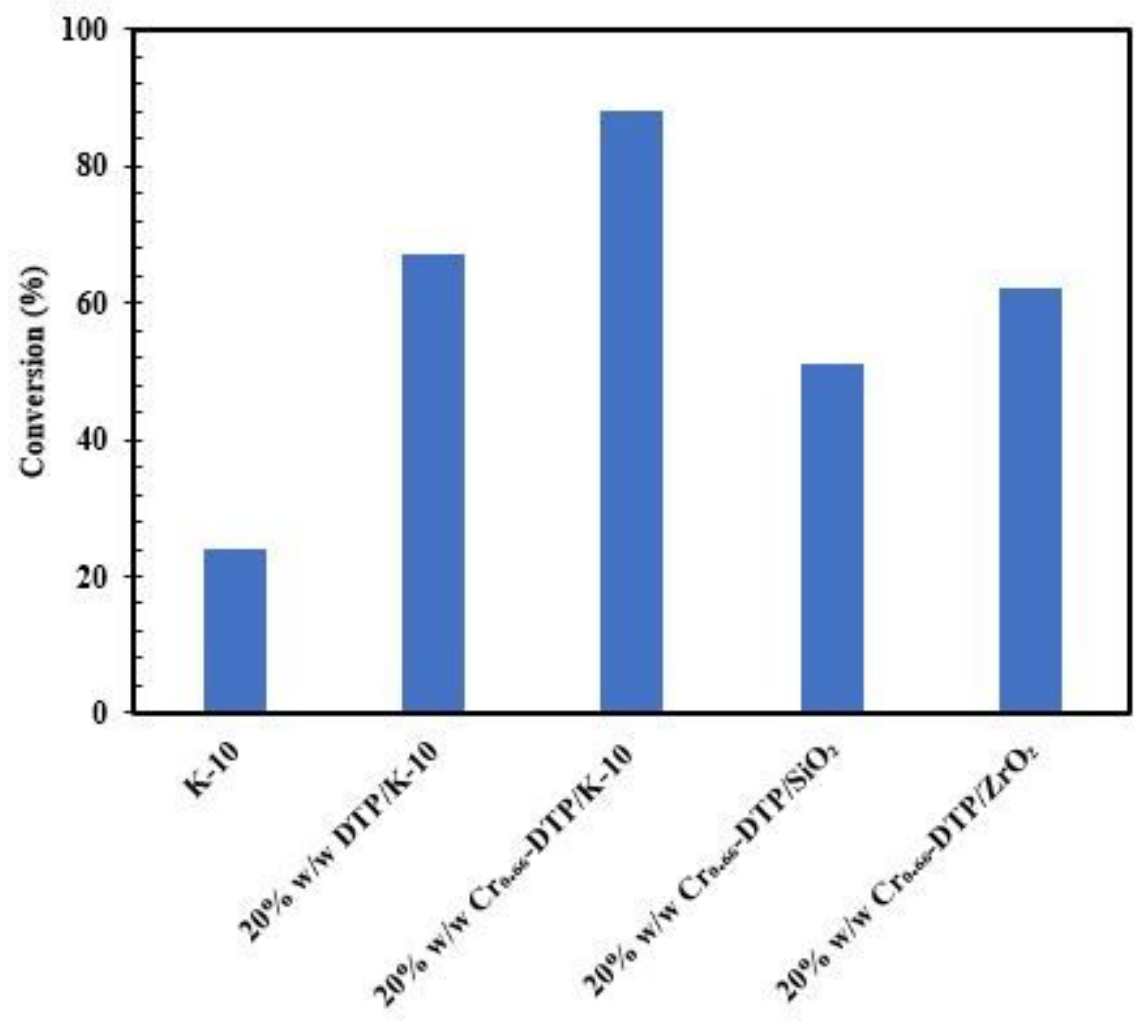


Figure 3

Effect of various catalysts on conversion of furan: Furan $2.50 \mathrm{~g}(0.036 \mathrm{~mol})$, acetic anhydride $18.74 \mathrm{~g}$ $(0.18 \mathrm{~mol})$, catalyst loading $0.0125 \mathrm{~g} / \mathrm{cm} 3$, speed of agitation $1000 \mathrm{rpm}$, temperature $50^{\circ} \mathrm{C}$, total volume $20 \mathrm{~cm} 3$, reaction time $180 \mathrm{~min}$.

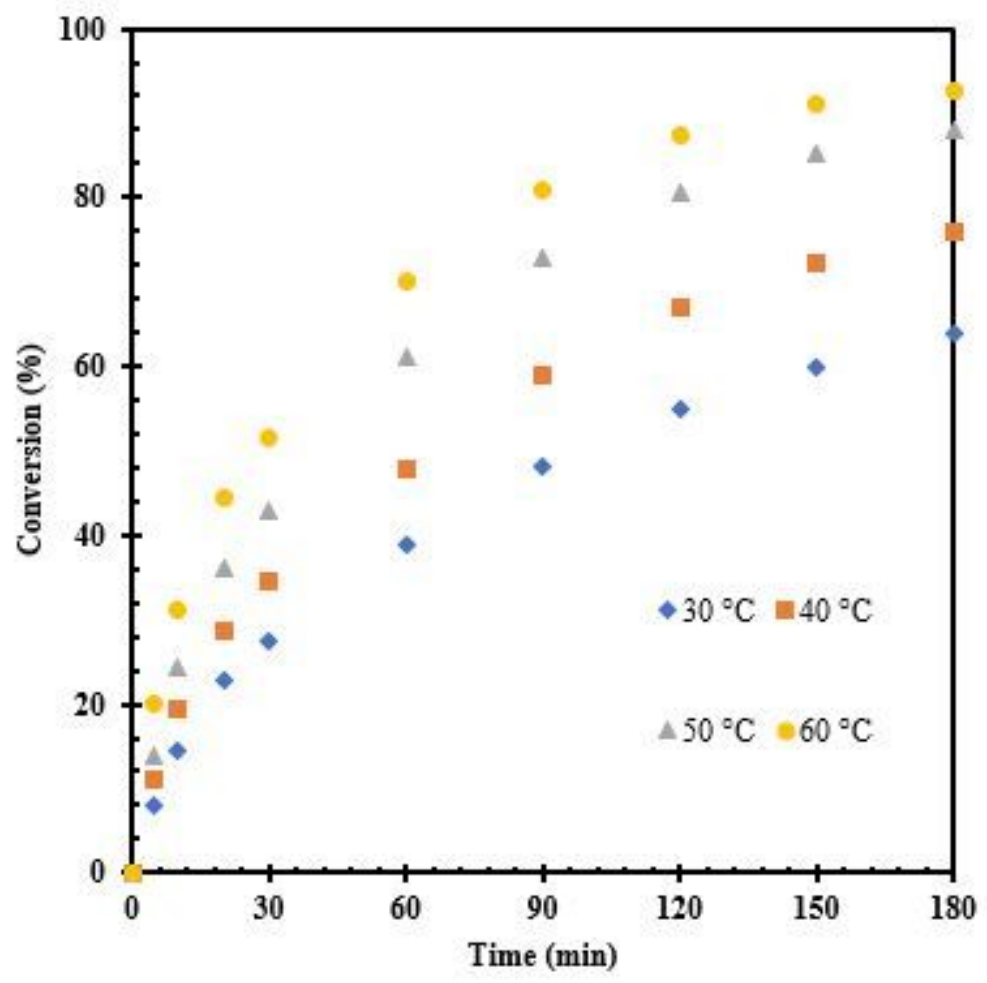

\section{Figure 4}

Effect of temperature on conversion of furan: Furan $2.50 \mathrm{~g}(0.036 \mathrm{~mol})$, acetic anhydride $18.74 \mathrm{~g}(0.18$ $\mathrm{mol}$ ), catalyst loading $0.0125 \mathrm{~g} / \mathrm{cm} 3$, speed of agitation $1000 \mathrm{rpm}$, total volume $20 \mathrm{~cm} 3$, reaction time $180 \mathrm{~min}$.
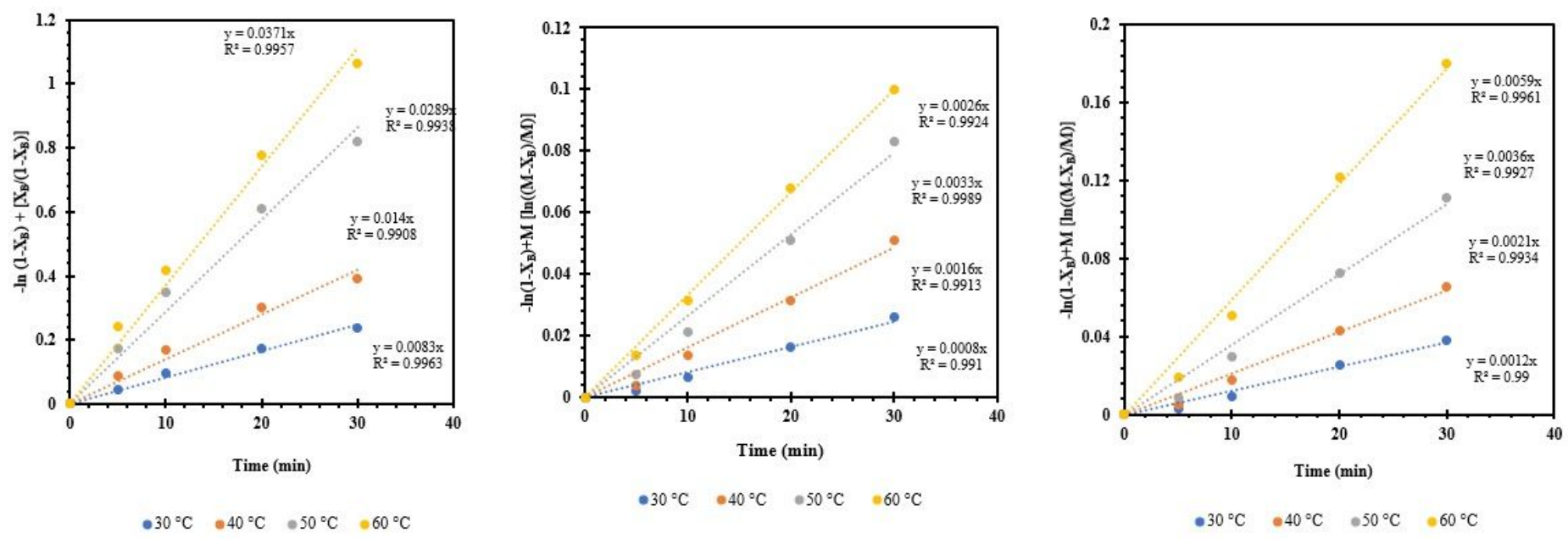
Figure 5

(a). Plot of $-\ln (1-X B)+[X B /(1-X B)]$ vs. time for $M=1$.(b). Plot of $\ln (1-X B)+M[\ln ((M-X B) / M)]$ vs. time for $M=3$.(c). Plot of $\ln (1-X B)+M[\ln ((M-X B) / M)]$ vs. time for $M=5$.

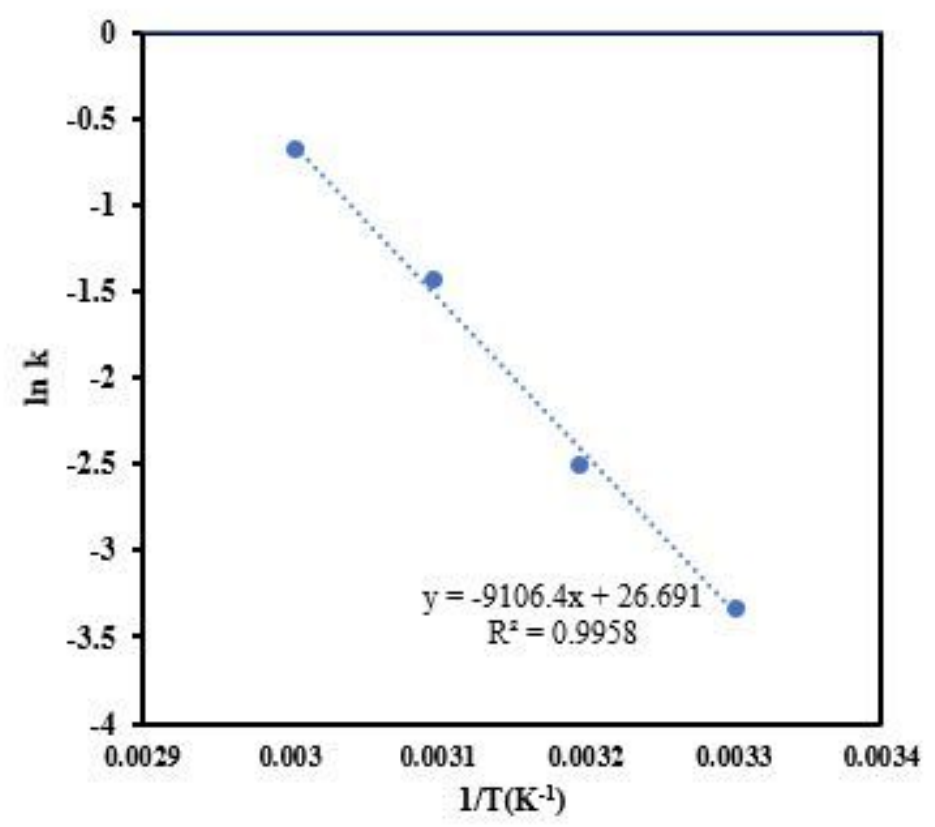

Figure 6

Arrhenius Plot

\section{Supplementary Files}

This is a list of supplementary files associated with this preprint. Click to download.

- 4.ESIDSDGDY11012021.docx 